\title{
Apigenin enhances the cisplatin cytotoxic effect through p53-modulated apoptosis
}

\author{
RUI LIU ${ }^{1}$, PING JI ${ }^{2}$, BIN LIU ${ }^{1}$, HAISHI QIAO ${ }^{2}$, XIA WANG ${ }^{1}$, LIKUN ZHOU ${ }^{1}$, TING DENG ${ }^{1}$ and YI BA $^{1}$ \\ ${ }^{1}$ Department of Gastrointestinal Oncology, Tianjin Key Laboratory of Cancer Prevention and Therapy, \\ Tianjin Medical University Cancer Institute and Hospital, Tianjin 300060; ${ }^{2}$ Jiangsu Key Laboratory of Molecular Medicine, \\ Nanjing University Medical School, Nanjing, Jiangsu 210093, P.R. China
}

Received June 14, 2015; Accepted November 7, 2016

DOI: $10.3892 / \mathrm{ol} .2016 .5495$

\begin{abstract}
Epidemiological and experimental evidence suggests that dietary flavonoids, including apigenin, have anticancer roles. Apigenin has been reported to elevate p53, a critical molecule in the induction of apoptosis. The present study aimed to investigate whether apigenin, a dietary flavonoid, improves the cytotoxic effect of cisplatin in a cancer cell culture system, and to elucidate the mechanism of this effect. Multiple tumor cell types were treated with apigenin, cisplatin or both drugs. Cell viability was evaluated, and the cytotoxic effect was determined biochemically and microscopically. Treatment with apigenin increased cisplatin-induced DNA damage and the apoptosis of tumor cells in a p53-dependent manner. Apigenin, when used with cisplatin, inhibited cell proliferation and promoted mitogen-activated protein kinase activation and subsequent p53 phosphorylation, leading to p53 accumulation and upregulation of proapoptotic proteins. Cisplatin is one of the most commonly used chemotherapeutic drugs for malignant tumors, but resistance to this drug occurs. The current results therefore demonstrate that dietary flavonoids may diminish the resistance of cancers to cisplatin.
\end{abstract}

\section{Introduction}

Polyphenols, such as epigallocatechin gallate, resveratrol and flavonoids, exist in nature (1). Flavonoids are a group of polyphenols that share similar chemical features and are abundant in vegetables, fruits and tea, amongst other products (2). Humans absorb a large amount of flavonoids orally, and epidemiological studies have revealed that the risk of certain types of cancer, particularly cancers of the breast, digestive tract, skin, prostate and certain hematological malignancies, is inversely correlated with intake of flavonoids $(3,4)$. Flavonoids possess antioxidative,

Correspondence to: Dr Yi Ba, Department of Gastrointestinal Oncology, Tianjin Key Laboratory of Cancer Prevention and Therapy, Tianjin Medical University Cancer Institute and Hospital, 19 Huanhuxi Road, Tianjin 300060, P.R. China

E-mail: yiba99@yahoo.com

Key words: apigenin, cisplatin, apoptosis, p53, cancer anti-inflammatory and antitumor properties (5). A number of flavonoid compounds have previously been demonstrated to enhance the effects of conventional chemotherapeutic drugs in cancer cells, prompting increased attention (6-8).

Apigenin (4',5,7-trihydroxyflavone) is a promising chemopreventive agent that is abundantly present in fruits, vegetables, and teas (3). This compound has anticarcinogenic properties via diverse mechanisms and is suggested to have a tumor preventative effect $(3,9)$. The mechanism of action of apigenin appears to involve p53, as apigenin $(15-60 \mu \mathrm{M})$ has previously been reported to induce the necrosis and apoptosis of neuroblastoma cells expressing wild-type, but not mutant, p53. Apigenin was suggested to elevate the levels of p53, and p53 effector gene expression in these neuroblastoma cells (10). Apigenin also causes cell cycle arrest and sensitizes leukemia cells to vincristine (11). Apigenin has additionally been reported to induce apoptosis of prostate and colon cancer cells through induction of death receptor 5, and to act synergistically with exogenous tumor necrosis factor-related apoptosis-inducing ligand to induce cell apoptosis (12). Furthermore, apigenin enhances the anticancer activity or minimizes the resistance of cancer cells to a number chemotherapeutics, including gemcitabine, paclitaxel, 5-fluorouracil and doxorubicin by inducing apoptosis (13-17). It was reported that apigenin sensitizes neuroblastoma cells to the anticancer drug etoposide by retention of p53 in cell nuclei (18).

The present study aimed to determine the effects of apigenin on cisplatin cytotoxic activity using several tumor cell lines, and to elucidate the potential mechanisms of this. Cisplatin is a member of a class of platinum-containing anticancer drugs, which has demonstrated therapeutic properties against a broad range of cancers $(19,20)$. Cisplatin exerts a DNA-binding effect by cross-linking DNA in several different ways, interfering with mitotic cell division. The damaged DNA prompts induction of DNA repair mechanisms, which activates apoptotic mechanisms when repair proves impossible (21). Many tumors demonstrate good responsiveness to this drug, but drug resistance eventually develops, particularly in patients with lung, colorectal, prostate and ovarian cancer (22). Several approaches have been proposed to maintain cisplatin efficacy, including increased accumulation or stabilization of p53, upregulating reactive oxygen species production and inhibiting NF- $\mathrm{NB}$ and antiapoptotic proteins (23-26). The current study investigated the effects of apigenin on p53 accumulation, and its effect on cisplatin 
cytotoxic activity in several tumor cell lines. The present results demonstrated that apigenin enhances the inhibition of proliferation observed following cisplatin treatment in a p53-dependent manner, potentially enhancing the antitumor effects of cisplatin.

\section{Materials and methods}

Cell culture and inhibition of cell growth. The HeLa, A549, HCT 116, H1299, and MCF-7 cells were obtained from the Cell Bank of the Chinese Academy of Sciences and cultured in high-glucose Dulbecco's Modified Eagle's medium (Thermo Fisher Scientific, Inc., Waltham, MA, USA). H1299 cells were cultured in RPMI 1640 medium (Thermo Fisher Scientific, Inc.). Apigenin, U0126 (a mitogen-activated protein kinase kinase inhibitor), MTT (all Sigma-Aldrich; Merck Millipore, Darmstadt, Germany) and cisplatin (Jiangsu Hansoh Pharm. Co., Ltd., Lianyungang, China) were obtained commercially. To determine the effect of the compounds on cell viability, MTT assays were performed. Briefly, $\sim 5 \times 10^{3}$ cells per well were seeded in 96-well plates (Corning Incorporated, Corning, $\mathrm{NY}$, USA ) for $24 \mathrm{~h}$ at $37^{\circ} \mathrm{C}$. The cells were treated in triplicate with apigenin (in DMSO; final concentration, $\leq 0.1 \%$ ) or cisplatin (in PBS). These treatments were $30 \mu \mathrm{M}$ apigenin for $2 \mathrm{~h}$, followed by different doses of cisplatin $(2.5,5.0$ and $10 \mu \mathrm{M}$ ) for another $48 \mathrm{~h}$. At the end of treatment, MTT was added to determine cell viability as previously reported (27).

Western blotting. Western blotting was performed to monitor protein expression and modifications using a standard protocol (28). Briefly, total protein was extracted from the cultured cells using lysis buffer (Sigma-Aldrich; Merck Millipore). The proteins were separated by $10 \%$ SDS-PAGE and then transferred onto polyvinylidene difluoride membranes. The membranes were blocked with $2 \%$ bovine serum albumin (Roche Diagnostics, Basel, Switzerland) at room temperature for $1 \mathrm{~h}$ and incubated overnight at $4^{\circ} \mathrm{C}$ with primary antibodies. The primary antibodies were against caspase-3 (catalog no. 9662S; dilution, 1:1,000), caspase-9 (catalog no. 9502S; dilution, 1:1,000), poly ADP ribose polymerase (PARP; catalog no. 9542S; dilution, 1:2,000), c-Jun N-terminal kinase (JNK1/2; catalog no. 9252S; dilution, 1:1,000), p-JNK (catalog no. 9251S; dilution, 1:1,000), p38 (catalog no. 9212S; dilution, 1:1,000), p-p38 (catalog no. 9211S; dilution, 1:1,000), cleaved caspase-9 (catalog no. 9501S; dilution, 1:1,000), cleaved caspase-3 (catalog no. 9661S; dilution, 1:2,000) (all Cell Signaling Technology, Inc., Danvers, MA, USA), extracellular signal-regulated kinase (Erk)2 (catalog no. sc-154; dilution, 1:4,000), p-Erk (catalog no. sc-7383; dilution, 1:1,000), caspase-8 (catalog no. sc-56070, dilution, 1:1,000), Bax (catalog no. sc-493; dilution, 1:200), p53 (catalog no. sc-47698; dilution, 1:1,000), p-p53/Ser15 (catalog no. sc-101762; dilution, 1:1,000), mouse double minute 2 homolog (MDM2; catalog no. sc-5304; dilution, 1:1,000) (all Santa Cruz Biotechnology, Inc., Dallas, TX, USA), cleaved caspase-8 (catalog no. PA5-35558; dilution, 1:1,000; Invitrogen; Thermo Fisher Scientific, Inc.) and GAPDH (catalog no. AG019; 1:500; Beyotime Institute of Biotechnology, Haimen, China). After washing, the membranes were incubated with the horseradish peroxidase-conjugated secondary antibody (anti-mouse; catalog no. A3682-1ML; dilution, 1:80,000; and anti-rabbit; catalog no. A0545-1ML; dilution, 1:80,000; Abcam, Cambridge, UK) overnight at $4^{\circ} \mathrm{C}$. The images were captured using a FluorChem HD2 imaging system (Protein Simple, San Jose, CA, USA) following incubation with an enhanced chemiluminescence reagent kit (Pierce; Thermo Fisher Scientific, Inc.). Protein expression levels were compared with GAPDH expression. The blots were quantified using Adobe Photoshop CS6 (Adobe Inc., San Jose, CA, USA).

DAPI staining. Cell nuclei were stained with 4', 6-diamidino-2-phenylindole (DAPI) to reveal morphological changes. Briefly, cells $\left(1 \times 10^{5} / \mathrm{ml}\right)$ were grown for $24 \mathrm{~h}$ at $37^{\circ} \mathrm{C}$ on sterilized, fibronectin-coated coverslips to allow cells to attach and spread. The cells were treated with the apigenin and cisplatin $(50,100,150$ or $200 \mathrm{mg} / \mathrm{ml})$ for $48 \mathrm{~h}$, fixed using $4 \%$ paraformaldehyde and stained with $50 \mu \mathrm{l} /$ well of DAPI (1:2,000 dilution in TBST) for $5 \mathrm{~min}$. The cells were then imaged under a BX-53 fluorescence microscope (Olympus Corporation, Tokyo, Japan) equipped with the QImaging system (Surrey, BC, Canada).

Reverse transcription-quantitative polymerase chain reaction (RT-qPCR). RT-qPCR was performed to determine p53 gene expression in apigenin and apigenin-cisplatin treated cells. Total RNA was extracted from the cultured cells using TRIzol reagent (Invitrogen; Thermo Fisher Scientific, Inc.), according to the manufacturer's protocol. RT was performed using $5 \mathrm{X}$ AMV buffer, AMV enzyme, $10 \mathrm{mM}$ dNTP and R-primer (Takara Bio Inc., Otsu, Japan) at $16^{\circ} \mathrm{C}$ for $15 \mathrm{~min}, 42^{\circ} \mathrm{C}$ for $1 \mathrm{~h}$ and $85^{\circ} \mathrm{C}$ for 5 min. p53 levels were determined with RT-qPCR. PCR was perfomed using 10X PCR buffer, $10 \mathrm{mM}$ dNTP, Taq enzyme and primers from Takara Inc., and SYBR Green from Applied Biosystems (Thermo Fisher Scientific, Inc.). The following primers were used to amplify the p53 gene: Forward primer, 5'-AACGGTACTCCGCCACC and reverse primer, 5'-CGT GTCACCGTCGTGGA. The following primers were used for the GAPDH gene: Forward, 5'-ACCACAGTCCATGCCATC AC-3' and reverse, 5'-TCCACCACCCTGTTGCTGTA-3'. The cycling conditions were as follows: $95^{\circ} \mathrm{C}$ for $5 \mathrm{~min}, 95^{\circ} \mathrm{C}$ for $15 \mathrm{sec}$ and $60^{\circ} \mathrm{C}$ for $1 \mathrm{~min}$, for 40 cycles. The relative amount of gene normalized to control was calculated using the $2^{-\Delta \Delta \mathrm{Cq}}$ method (29). The mean Cq was calculated from triplicate PCRs.

Statistical analysis. All data were performed at least in triplicate. The results were presented as the mean \pm standard deviation of at least three independent experiments. Statistical analysis was performed using Student's t-test by utilizing IBM SPSS Statistics, version 20.0 (IBM, Armonk, NY, USA). P<0.05 was used to indicate a statistically significant difference.

\section{Results and Discussion}

Apigenin enhances the cytotoxic effect of cisplatin. To study the effect of apigenin on cisplatin-induced cell death, A549, MCF-7, HCT 116 and HeLa cells that possess wild-type p53 and H1299 cells, which are p53-null due to homozygous deletion of the TP53 gene (30), were treated with apigenin for $2 \mathrm{~h}$, followed by different doses of cisplatin for $48 \mathrm{~h}$, as indicated. The cells were visually inspected under an inverted fluorescence microscope at 24 and $48 \mathrm{~h}$ after cisplatin treatment. Cisplatin treatment caused cell death at $48 \mathrm{~h}$. The effect was quantitatively measured using an MTT assay. As reported 


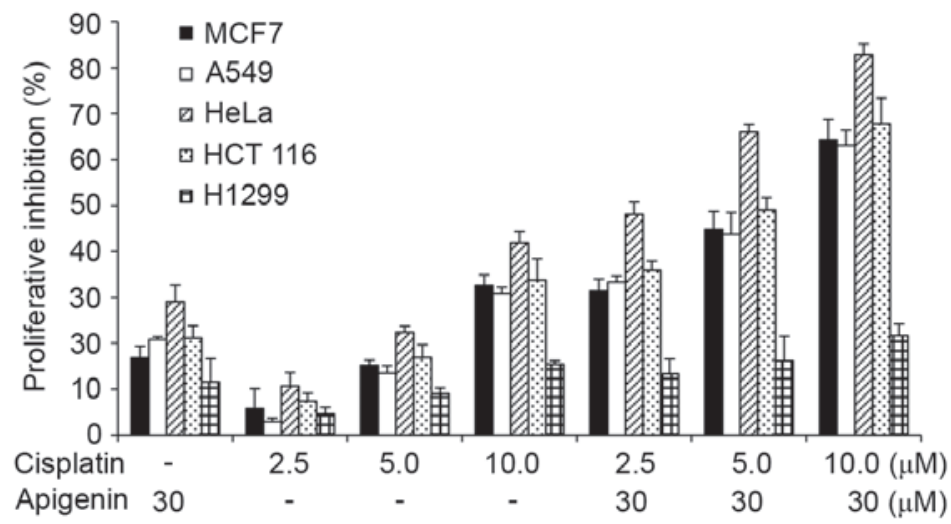

Figure 1. Effect of apigenin and cisplatin on proliferative inhibition of different cancer cell lines, determined by MTT assay. MCF-7, A549, HeLa, HCT 116, or $\mathrm{H} 1299$ cells were treated with $30 \mu \mathrm{M}$ apigenin for $2 \mathrm{~h}$, followed by different concentrations $(0,2.5,5$ or $10 \mu \mathrm{M})$ of cisplatin for a further $48 \mathrm{~h}$. The bars represent mean + standard deviation of results obtained from three independent experiments.

A
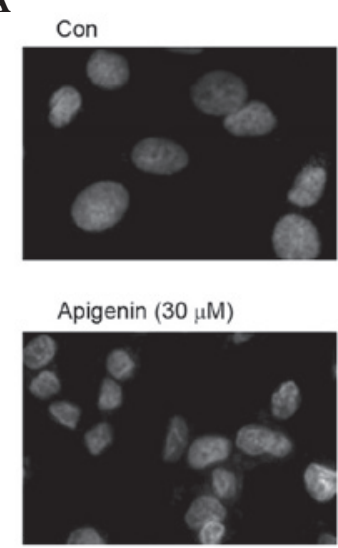

B

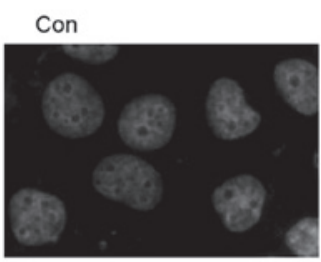

Apigenin $(30 \mu \mathrm{M})$

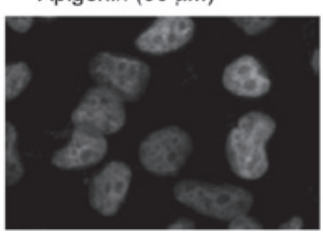

Cisplatin $(10 \mu \mathrm{M})$

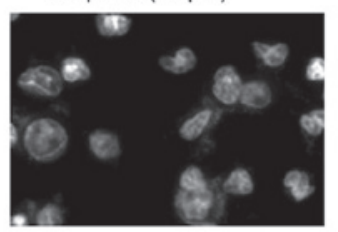

Apigenin/Cisplatin

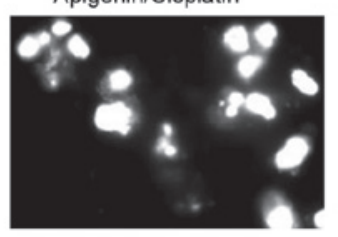

Cisplation $(10 \mu \mathrm{M})$

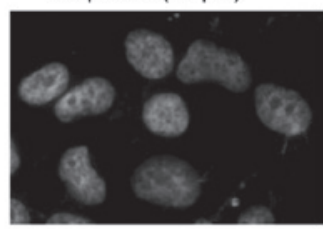

Apigenin/Cisplatin

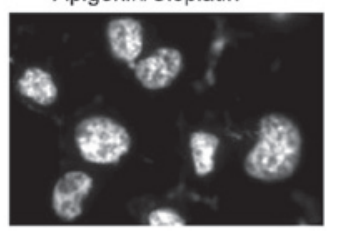

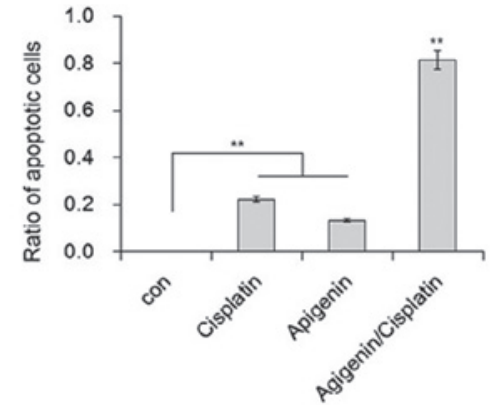

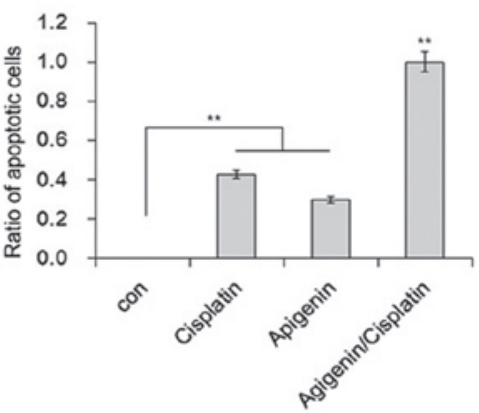

Figure 2. Effect of apigenin and cisplatin on nuclear morphology of cancer cells. (A) A549 or (B) H1299 cells were treated with $30 \mu \mathrm{M}$ apigenin for 2 h, followed by $10 \mu \mathrm{M}$ cisplatin for another $48 \mathrm{~h}$. The cells were stained with DAPI and examined under a fluorescence microscope (magnification, $\mathrm{x} 40$ ). ${ }^{* *} \mathrm{P}<0.01$. Con, control.

in Fig. 1, apigenin treatment alone caused a low viablity of cells to $10-30 \%$ in all cell lines, while cisplatin treatment alone caused a viability of $3 \%$ at low doses to $42 \%$ at higher concentrations in HeLa cells. Co-treatment of apigenin at $30 \mu \mathrm{M}$ with cisplatin at 2.5, 5.0, and $10.0 \mu \mathrm{M}$ increased the inhibitory effect of cisplatin in all cell lines tested, except the H1299 cells.

Apigenin enhances cisplatin-induced apoptosis. Cisplatin appeared to exert a cytotoxic effect via the induction of apoptosis. Marked cell shrinkage resembling cell apoptosis was observed in apigenin plus cisplatin-treated samples. To confirm whether this shrinkage was due to apoptosis, DAPI staining was performed to illustrate the nuclear morphology of A549 and H1299 cells. Although a proportion of A549 cells demonstrated chromatin condensation in cells treated with cisplatin, inclusion of apigenin resulted in marked changes to chromatin condensation, nuclear shrinkage and the formation of apoptotic bodies in A549 cells (Fig. 2A). 

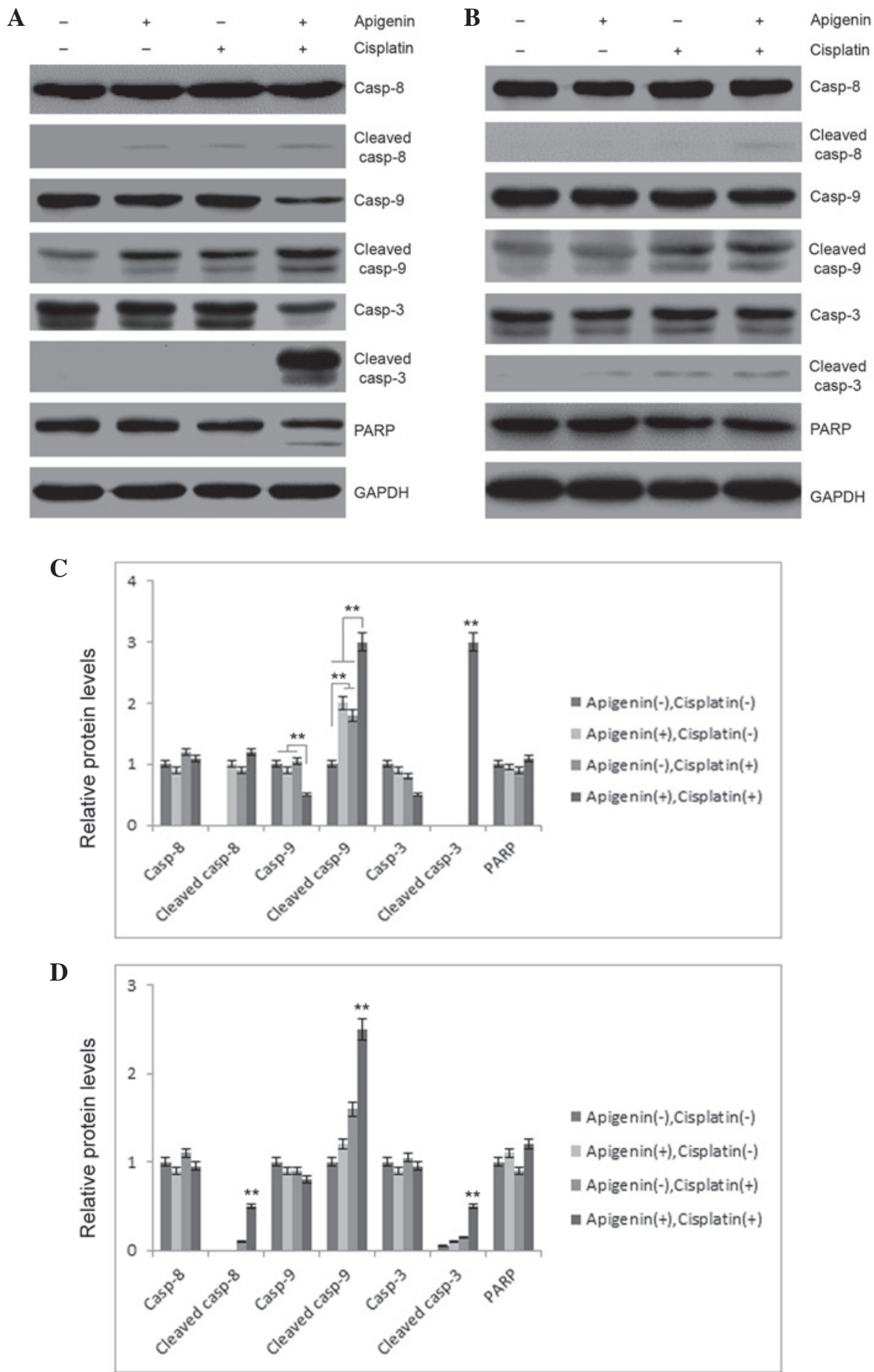

Figure 3. Effect of apigenin and cisplatin on caspase activation. (A) A549 or (B) H1299 cells were treated with $30 \mu \mathrm{M}$ apigenin for $2 \mathrm{~h}$, followed by $10 \mu \mathrm{M}$ cisplatin for another $48 \mathrm{~h}$. Casp-3, -8 and -9 expression and their cleavage or PARP degradation in the two cell lines was evaluated by western blotting. (C) Semi-quantification of (A). (D) Semi-quantification of (B). Casp, caspase; PARP, poly ADP ribose polymerase; GAPDH, glyceraldehyde 3-phosphate dehydrogenase. ${ }^{* *} \mathrm{P}<0.01$

In comparison, no nuclear fragmentation was observed in the H1299 cells under the same conditions, although the formation of heterochromatin foci was apparent in these cells (Fig. 2B). These results indicate that apigenin is likely responsible for the apoptotic effect of cisplatin in A549 cells.

To investigate these results, the role of apigenin and cisplatin treatment in caspase activation was examined. As reported in Fig. 3A, apigenin $(30 \mu \mathrm{M})$ or cisplatin $(10 \mu \mathrm{M})$ treatment in A549 cells resulted in partial cleavage of caspase- 9 , while no marked cleavage of caspase- 3 or -8 was detected in these samples. Combined application of apigenin and cisplatin caused significant cleavage of caspase-3 and -9 . Concomitantly, PARP cleavage was also detected in apigenin and cisplatin-treated cells (Fig. 3A), indicating that combined application of apigenin and cisplatin promoted activation of caspase-3 and -9. However, combinatorial treatment did not cause significant cleavage of these caspases in H1299 cells, which are p53-null (Fig. 3B). These results indicated 

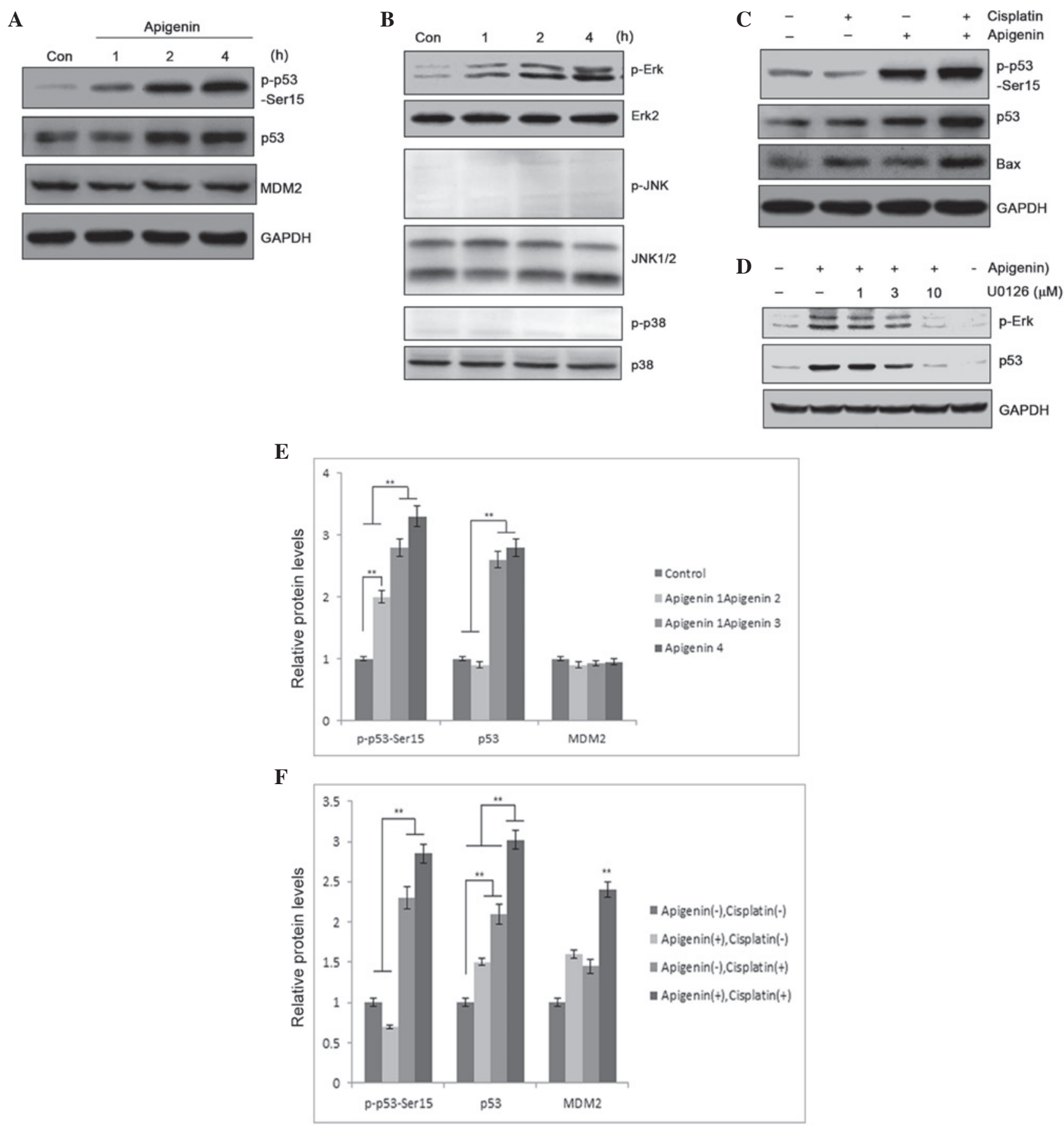

Figure 4. (A) p53 expression and 553 Ser-15 phosphorylation was determined by western blotting, following treatment of A549 cells with $30 \mu \mathrm{M}$ apigenin for 1,2 or $4 \mathrm{~h}$. (B) p53 and Bax expression, and p53 phosphorylation, as detected by western blotting, following treatment of A549 cells with $30 \mu \mathrm{M}$ apigenin for $2 \mathrm{~h}$, then $10 \mu \mathrm{M}$ cisplatin for another $24 \mathrm{~h}$. (C) MAPK pathway molecule activation, determined by protein phosphorylation levels, in A549 cells treated with $30 \mu \mathrm{M}$ apigenin for 15, 30,60 or $120 \mathrm{~min}$, reported by western blotting. (D) Erk/MAPK activation relative to p53 accumulation in A549 cells pretreated with U0126, an Erk/MAPK inhibitor, then treated with $10 \mu \mathrm{M}$ apigenin to induce Erk/MAPK activation. (E) Semi-quantification of (A). (F) Semi-quantification of (B). Con, control; MDM2, mouse double minute 2 homolog; GAPDH, glyceraldehyde 3-phosphate dehydrogenase; Erk, extracellular signal-regulated kinase; JNK, c-Jun N-terminal kinase; MAPK, mitogen-activated protein kinase. ${ }^{* *} \mathrm{P}<0.01$.

that apigenin amplified the apoptosis-inducing activity of cisplatin in A549 cells.

Apigenin promotes 553 phosphorylation and accumulation. p53 may be functionally compromised by its interaction with several proteins. Among those proteins, MDM2 serves as a pivotal negative regulator and counteracts p53 activation $(31,32)$. p53 is maintained at constant levels in quiescent cells as the protein undergoes constant degradation mediated by MDM2 and the proteasome (33). Factors that promote $\mathrm{N}$-terminal phosphorylation of p53 protein cause disruption of p53-MDM2 interaction, resulting in p53 accumulation and transcriptional regulation (34). In the present study, immunoblotting was performed in A549 cells to determine whether apigenin treatment caused p53 accumulation. In addition to increased accumulation of p53 protein in apigenin-treated samples, apigenin also dose-dependently induced p53 phosphorylation, as detected by a phospho-Ser15 specific antibody 
(Fig. 4A). Compared with treatment using cisplatin alone, combined treatment with apigenin and cisplatin significantly elevated the levels of p53 protein in the sample (Fig. 4B). Elevated p53 expression could may result from increased gene expression or from posttranslational modification, an event that can lead to p53 stabilization and accumulation (35). However, the levels of p53 mRNA in the A549 cells that were treated with apigenin and cisplatin for 6,12 and $24 \mathrm{~h}$ were not significantly altered, as determined by RT-PCR (data not shown); this suggests that elevated expression of p53 protein was likely to be associated with decreased degradation. Notably, increased p53 accumulation was associated with increased detection of Bax, a proapoptotic protein, in the samples (Fig. 4B), suggesting that apigenin amplified the cisplatin cytotoxic effect through induction of p53 accumulation and p53-regulated proapoptotic gene expression.

Erk/mitogen-activated protein kinase (MAPK) activation is responsible for induced p53 phosphorylation. MAPK activation has a critical role in p53 phosphorylation, which may promote p53 stabilization (36). An immunoblotting analysis was performed in A549 cells to determine whether apigenin treatment activated MAPK. Apigenin treatment was revealed to selectively activate the Erk/MAPK pathway, while no activation of JNK or p38 MAPK was detected in apigenin-treated A549 cells (Fig. 4C). Erk/MAPK activation was determined to be responsible for p53 phosphorylation, as pretreatment with U0126, a specific inhibitor that blocks Erk/MAPK pathway activation (37), dose-dependently blocked apigenin-induced p53 phosphorylation (Fig. 4D). This suggests that Erk/MAPK pathway activation is a contributing factor in apigenin-induced p53 accumulation. These results indicate that apigenin sensitizes tumor cells to the cisplatin-associated cytotoxic effect via modification of the p53 protein.

Apigenin is a dietary flavonoid that is hypothesized to have a beneficial role in cancer chemotherapy (38). This compound has been reported to induce cell cycle arrest, in addition to apoptosis when used at varying concentrations (39). In the current study, apigenin had the ability to amplify cisplatin-induced apoptosis of cancer cells. Apigenin treatment induced MAPK activation and subsequent p53 phosphorylation, leading to its accumulation and increased effector gene activation. In addition, increased caspase activation was also detected in samples treated with both cisplatin and apigenin, suggesting that apigenin sensitizes A549 cells to induced apoptosis through p53 accumulation and altered effector gene regulation.

As a tumor suppressor, p53 has an important role in genome stability and functions as a critical tumor suppressor that is involved in preventing cancer (40). Multiple studies have verified the important role p53-dependent apoptosis has in inhibiting carcinogenesis (41). Cell lines of lung cancer (A549), breast cancer (MCF-7), colorectal cancer (HCT 116) and cervical cancer (HeLa) that possess wild-type p53, and the lung cancer line H1299, which does not generate functional p53, were therefore examined, and the effects of combined treatment of cisplatin with apigenin was determined in these cells. Apigenin notably amplified the inhibitory effect on proliferation of cisplatin in cells with wild-type p53, but not in the p53-null H1299 cells. This was supported by the observed increased activation of caspases-9 and -3 , and the nuclear morphological changes in A549 cells.

Posttranslational modification has a critical role in p53 function $(42,43)$. Consistent with this, increased phosphorylation and accumulation of p53 was detected in apigenin-treated samples. Apigenin significantly enhanced p53 phosphorylation. Increased p53 phosphorylation was revealed to be modulated by MAPK, as apigenin treatment promoted MAPK activation; this was blocked by application of U0126, a specific inhibitor of the Erk/MAPK pathway. It is of note that the timing of MAPK (60 min) and p53 ( $2 \mathrm{~h}$ ) activation potentially suggest a sequential effect of these events, indicating that MAPK activation may have a crucial role in p53 accumulation and the proapoptotic effect.

Apigenin has demonstrable activity in reducing oxidative stress, inducing cell cycle inhibition and apoptosis, and as an anti-inflammatory agent (44). Foods high in apigenin include celery, parsley, tomatoes and red wine $(45,46)$. Apigenin is generally considered to be safe when consumed in plant foods, with no toxic or mutagenic effects previously reported (47). In a population-based case-control study that included 1,141 patients with ovarian cancer and 1,183 women of similar age to assess the content of their diets, it was reported that flavonoid intake lowered the risk of ovarian cancer (48). The current results demonstrate that dietary flavonoids like apigenin sensitize tumor cells to chemotherapeutic agents. Therefore, combined treatment of tumor cells with conventional chemotherapeutic drugs and dietary supplements provides a promising direction for cancer chemotherapy.

Apigenin enhances the cytotoxic effect of cisplatin during apoptosis in tumor cells, promotes p53 phosphorylation and accumulation, and the Erk/MAPK pathway was revealed to be focal in apigenin-induced p53 accumulation.

\section{Acknowledgements}

The present work was supported by National Natural Science Foundation of China (grant nos. 81201946 and 81372394), Ministry of Education Research Fund for Doctoral Programmes (grant no. 2012202120013), the Science Foundation of the Medical University Of Tianjin (grant no. 2011KY15), the National Research Platform of Clinical Evaluation Technology for New Anticancer Drugs (grant no. 2013ZX09303001). The authors thank Xiaoyan Li and Ziying Yang for their technical assistance and Dr Erguang Li for English editing.

\section{References}

1. Afzal M, Safer AM and Menon M: Green tea polyphenols and their potential role in health and disease. Inflammopharmacology 23: 151-161, 2015.

2. Altemimi A, Watson DG, Kinsel M and Lightfoot DA: Simultaneous extraction, optimization, and analysis of flavonoids and polyphenols from peach and pumpkin extracts using a TLC-densitometric method. Chem Cent J 9: 39, 2015.

3. Shukla S and Gupta S: Apigenin: A promising molecule for cancer prevention. Pharm Res 27: 962-978, 2010.

4. Kris-Etherton PM, Hecker KD, Bonanome A, Coval SM, Binkoski AE, Hilpert KF, Griel AE and Etherton TD: Bioactive compounds in foods: Their role in the prevention of cardiovascular disease and cancer. Am J Med 113 (Suppl 9B): 71S-88S, 2002. 
5. Yang S, Zhang H, Yang X, Zhu Y,and Zhang M: Evaluation of antioxidative and antitumor activities of extracted flavonoids from Pink Lady apples in human colon and breast cancer cell lines. Food Funct 6: 3789-3798, 2015.

6. Trudel D, Labbé DP, Bairati I, Fradet V, Bazinet L and Têtu B: Green tea for ovarian cancer prevention and treatment: A systematic review of the in vitro, in vivo and epidemiological studies. Gynecol Oncol 126: 491-498, 2012.

7. Gupta SC, Kannappan R, Reuter S, Kim JH and Aggarwal BB: Chemosensitization of tumors by resveratrol. Ann N Y Acad Sci 1215: 150-160, 2011.

8. Nessa MU, Beale P, Chan C, Yu JQ and Huq F: Synergism from combinations of cisplatin and oxaliplatin with quercetin and thymoquinone in human ovarian tumour models. Anticancer Res 31: 3789-3797, 2011.

9. Patel D, Shukla S and Gupta S: Apigenin and cancer chemoprevention: Progress, potential and promise (review). Int J Oncol 30: 233-245, 2007

10. Torkin R, Lavoie JF, Kaplan DR and Yeger H: Induction of caspase-dependent, p53-mediated apoptosis by apigenin in human neuroblastoma. Mol Cancer Ther 4: 1-11, 2005.

11. Ruela-de-Sousa RR, Fuhler GM, Blom N, Ferreira CV, Aoyama H and Peppelenbosch MP: Cytotoxicity of apigenin on leukemia cell lines: Implications for prevention and therapy. Cell Death Dis 1: e19, 2010.

12. Horinaka M, Yoshida T, Shiraishi T, Nakata S, Wakada M and Sakai T: The dietary flavonoid apigenin sensitizes malignant tumor cells to tumor necrosis factor-related apoptosis-inducing ligand. Mol Cancer Ther 5: 945-951, 2006.

13. Strouch MJ, Milam BM, Melstrom LG, McGill JJ, Salabat MR, Ujiki MB, Ding XZ and Bentrem DJ: The flavonoid apigenin potentiates the growth inhibitory effects of gemcitabine and abrogates gemcitabine resistance in human pancreatic cancer cells. Pancreas 38: 409-415, 2009.

14. Xu Y, Xin Y, Diao Y, Lu C, Fu J, Luo L and Yin Z: Synergistic effects of apigenin and paclitaxel on apoptosis of cancer cells PLoS One 6: e29169, 2011.

15. Angelini A, Di Ilio C, Castellani ML, Conti P and Cuccurullo F: Modulation of multidrug resistance p-glycoprotein activity by flavonoids and honokiol in human doxorubicin- resistant sarcoma cells (MES-SA/DX-5): Implications for natural sedatives as chemosensitizing agents in cancer therapy. J Biol Regul Homeost Agents 24: 197-205, 2010

16. Choi EJ and Kim GH: 5-Fluorouracil combined with apigenin enhances anticancer activity through induction of apoptosis in human breast cancer MDA-MB-453 cells. Oncol Rep 22 $1533-1537,2009$

17. Wong IL, Chan KF, Tsang KH, Lam CY, Zhao Y, Chan TH and Chow LM: Modulation of multidrug resistance protein 1 (MRP1/ABCC1)-mediated multidrug resistance by bivalent apigenin homodimers and their derivatives. J Med Chem 52: 5311-5322, 2009.

18. Cai X and Liu X: Inhibition of Thr-55 phosphorylation restores p53 nuclear localization and sensitizes cancer cells to DNA damage. Proc Natl Acad Sci USA 105: 16958-16963, 2008.

19. Chabner BA and Roberts TG Jr: Timeline: Chemotherapy and the war on cancer. Nat Rev Cancer 5: 65-72, 2005

20. Billecke C, Finniss S, Tahash L, Miller C, Mikkelsen T, Farrell NP and Bögler O: Polynuclear platinum anticancer drugs are more potent than cisplatin and induce cell cycle arrest in glioma. Neuro Oncol 8: 215-226, 2006

21. Mendes F, Groessl M, Nazarov AA, Tsybin YO, Sava G, Santos I, Dyson PJ and Casini A: Metal-based inhibition of poly (ADP-ribose) polymerase-the guardian angel of DNA. J Med Chem 54: 2196-2206, 2011.

22. Galluzzi L, Senovilla L, Vitale I, Michels J, Martins I, Kepp O, Castedo M and Kroemer G: Molecular mechanisms of cisplatin resistance. Oncogene 31: 1869-1883, 2012.

23. Dhandapani KM, Mahesh VB and Brann DW: Curcumin suppresses growth and chemoresistance of human glioblastoma cells via AP-1 and NFKB transcription factors. J Neurochem 102: 522-538, 2007

24. Li Z, Musich PR and Zou Y: Differential DNA damage responses in p53 proficient and deficient cells: Cisplatin-induced nuclear import of XPA is independent of ATR checkpoint in p53-deficient lung cancer cells. Int J Biochem Mol Biol 2: 138-145, 2011.

25. Losert D, Pratscher B, Soutschek J, Geick A, Vornlocher HP, Müller M and Wacheck V: Bcl-2 downregulation sensitizes nonsmall cell lung cancer cells to cisplatin, but not to docetaxel. Anticancer Drugs 18: 755-761, 2007.
26. He F, Wang Q, Zheng XL, Yan JQ, Yang L, Sun H, Hu LN, Lin Y and Wang X: Wogonin potentiates cisplatin-induced cancer cell apoptosis through accumulation of intracellular reactive oxygen species. Oncol Rep 28: 601-605, 2012.

27. Chen X, Wang Z, Yang Z, Wang J, Xu Y, Tan RX and Li E: Houttuynia cordata blocks HSV infection through inhibition of NF- $\kappa B$ activation. Antiviral Res 92: 341-345, 2011.

28. Yang Z, Lee J, Ahn HJ, Chong CK, Dias RF and Nam HW: Western Blot Detection of Human Anti-Chikungunya Virus Antibody with Recombinant Envelope 2 Protein. Korean J Parasitol 54: 239-241, 2016

29. Livak KJ and Schmittgen TD: Analysis of relative gene expression data using real-time quantitative PCR and the 2(-Delta Delta C(T)) Method. Methods 25: 402-408, 2001.

30. Lin DL and Chang C: p53 is a mediator for radiation-repressed human TR2 orphan receptor expression in MCF-7 cells, a new pathway from tumor suppressor to member of the steroid receptor superfamily. J Biol Chem 271: 14649-14652, 1996.

31. Stindt MH, Muller PA, Ludwig RL, Kehrloesser S, Dötsch V and Vousden KH: Functional interplay between MDM2, p63/p73 and mutant p53. Oncogene 34: 4300-4310, 2015.

32. Heyne K, Förster J, Schüle R and Roemer K: Transcriptional repressor NIR interacts with the p53-inhibiting ubiquitin ligase MDM2. Nucleic Acids Res 42: 3565-3579, 2014.

33. Ahn HJ, Kim KS, Shin KW, Lim KH, Kim JO, Lee JY, Kim J, Park JH, Yang KM, Baek KH, et al: Ell3 stabilizes p53 following CDDP treatment via its effects on ubiquitin-dependent and -independent proteasomal degradation pathways in breast cancer cells. Oncotarget 6: 44523-44537, 2015.

34. Zhao Z, Wu L, Shi H and Wu C: p53 N-terminal binding and stabilisation by PIAS3 inhibits MDM2-induced p53 ubiquitination and regulates cell growth. Mol Med Rep 9: 1903-1908, 2014.

35. Wang L, Wang L, Zhang S, Qu G, Zhang D, Li S and Liu S: Downregulation of ubiquitin E3 ligase TNF receptor-associated factor 7 leads to stabilization of p53 in breast cancer. Oncol Rep 29: 283-287, 2013.

36. Kitamura T, Fukuyo Y, Inoue M, Horikoshi NT, Shindoh M, Rogers BE, Usheva A and Horikoshi N: Mutant p53 disrupts the stress MAPK activation circuit induced by ASK1-dependent stabilization of Daxx. Cancer Res 69: 7681-7688, 2009.

37. Cui C, Wang P, Cui N, Song S, Liang H and Ji A: Sulfated polysaccharide isolated from the sea cucumber Stichopus japonicas promotes the SDF-1 $\alpha /$ CXCR4 axis-induced NSC migration via the PI3K/Akt/FOXO3a, ERK/MAPK, and NF- $\mathrm{KB}$ signaling pathways. Neurosci Lett 616: 57-64, 2016.

38. Kim B, Jung N, Lee S, Sohng JK and Jung HJ: Apigenin Inhibits Cancer Stem Cell-Like Phenotypes in Human Glioblastoma Cells via Suppression of c-Met Signaling. Phytother Res 30: 1833-1840, 2016

39. Seo HS, Ku JM, Choi HS, Woo JK, Jang BH, Go H, Shin YC and Ko SG: Apigenin induces caspase-dependent apoptosis by inhibiting signal transducer and activator of transcription 3 signaling in HER2-overexpressing SKBR3 breast cancer cells. Mol Med Rep 12: 2977-2984, 2015.

40. Cho Y, Gorina S, Jeffrey PD and Pavletich NP: Crystal structure of a p53 tumor suppressor-DNA complex: Understanding tumorigenic mutations. Science 265: 346-355, 1994.

41. Vazquez A, Bond EE, Levine AJ and Bond GL: The genetics of the p53 pathway, apoptosis and cancer therapy. Nat Rev Drug Discov 7: 979-987, 2008.

42. Vucic D, Dixit VM and Wertz IE: Ubiquitylation in apoptosis: A post-translational modification at the edge of life and death. Nat Rev Mol Cell Biol 12: 439-452, 2011.

43. Meek DW: Tumour suppression by p53: A role for the DNA damage response? Nat Rev Cancer 9: 714-723, 2009.

44. Guo H, Kong S, Chen W, Dai Z, Lin T, Su J, Li S, Xie Q, Su Z, $\mathrm{Xu}$ Y and Lai X: Apigenin mediated protection of OGD-evoked neuron-like injury in differentiated PC12 cells. Neurochem Res 39: 2197-2210, 2014.

45. Gazzani G, Daglia M and Papetti A: Food components with anticaries activity. Curr Opin Biotechnol 23: 153-159, 2012

46. Tang D, Chen K, Huang L and Li J: Pharmacokinetic properties and drug interactions of apigenin, a natural flavone. Expert Opin Drug Metab Toxicol 2: 1-8, 2016.

47. Chen L and Zhao W: Apigenin protects against bleomycin-induced lung fibrosis in rats. Exp Ther Med 11: 230-234, 2016.

48. Gates MA, Vitonis AF, Tworoger SS, Rosner B, Titus-Ernstoff L, Hankinson SE and Cramer DW: Flavonoid intake and ovarian cancer risk in a population-based case-control study. Int J Cancer 124: 1918-1925, 2009. 